\title{
Identifying Challenges in Implementing Sustainable Practices in a Developing Nation
}

\author{
Omidreza Saadatian (Correspondent author) \\ Faculty of Design and Architecture, Universiti Putra Malaysia, FRSB, Serdang, Selangor, 43400, Malaysia \\ Tel: 60-17-207-5459, 60-3-8946-4051, 60-3-8946-4004 fax E-mail: omid_saadatian@yahoo.com \\ Osman Mohd Tahir \\ Faculty of Design and Architecture, Universiti Putra Malaysia, FRSB, Serdang, Selangor, 43400, Malaysia \\ Tel: 60-3-8946-4051, 60-3-8946-4004 fax E-mail:osmanmt@putra.upm.edu.my \\ Kamariah binti Dola \\ Faculty of Design and Architecture, Universiti Putra Malaysia, FRSB, Serdang, Selangor, 43400, Malaysia \\ Tel: 60-3-8946-4051, 60-3-8946-4004 faxＥ-mail: drkamariahupm@gmail.com
}

\begin{abstract}
The South Pars Special Economic Energy Zone (SPSEEZ) is the largest petroleum zone in Iran and the second biggest gas producer in the world. It is now one of the world's most important eco-industrial poles. Despite the rapid development and activists' calls to sustainable path, there is little systematic effort in the assessment of industrial zones sustainability in developing countries. Iran, a nation that has ratified the Rio Declaration pact, has moved forward in order to achieve sustainable development. There have always been controversial debates due to its success. This paper employs survey, interview as well as observation to explore the perception of people on planning and sustainable development efforts and to identify the most important challenges at SPSEEZ. The result shows that the major impediment against sustainability is the lack of involvement from urban planners and the public during decision-making process. Finally, the paper contributes to the identification of the most urgent problems in SPSEEZ and the functions of different stakeholders as a reference for better sustainable development planning.
\end{abstract}

Keywords: Sustainable development, Stakeholders' perception, SPSEEZ

\section{Introduction}

The term sustainability is a very general concept and has too many interpretations (Clifton, 2009). Sustainable development is popularly described by Brundtland as "a development that meets the needs of present without compromising the ability of future generations to meet their own needs" (Sneddon et al, $2005 \mathrm{p} 4)$. Moreover, sustainable development is about reaching a balance between economic, social, and environmental goals, as well as people's participation in the planning process in order to gain their input and support (ibid). However, sustainable development is what the decision-makers or environmental planners mean when they address this term (Osman, 2006). Sustainable development in planning means to achieve five goals of sustainability which are: resource conservation, built environment, environment quality, social equality and political participation (Blowers, 1993). In short, the sustainable development concept is intuitively understandable, but remains difficult to be expressed in a concrete practical definition as it is interpreted differently from different field (Briassoulis, 2001). This term has become an increasingly essential parameter to be considered in the planning of urban zones (Choguill, 2008). In addition, the topic of sustainability has become increasingly important since it is considered a solution for eradicating global poverty (Nghia, 2010). Meanwhile, majority of scholars has agreed that sustainable development promotes environmental, economic, and social well-being and amenity for the present as well as future generations (Azapagic et al, 2000, Mitich, 2010). Recently, scholars and academics have shown interest in Middle-East issues that promoted discussions and analysis of the existing problems from a regional perspective within the global experience of practice (Saleh, 2004). Iran, as one of the developing countries in the Middle-East which has ratified the Rio declaration pact, has done some efforts to move forward in achieving sustainable development. However, it seems that Iran still lacks the system for evaluating its success level in achieving its goal (Afrakhteh, 2006). Despite the situation, this petroleum industry-based country is expanding more petroleum zones very rapidly (Karshenas, 1990). This kind of rapid development and its unpleasant effects in the neighborhood is not something new. In other Middle-eastern countries, these uncontrolled developments in the fringes, inadequate urban services, spiraling land prices and construction costs, proliferation of slums and degradation of the quality of urban environment are among the current problems affecting this region (Mandeli, 2008). In addition, the unavailability of adequate financial and human resources is predominantly a big challenge in these countries (Calo \& Parise, 2009).

The rapid urban growth in some petroleum zones apparently has neglected issues such as proper urban design, social issues and environmental effects. In this regard, a debate has emerged suggesting that this unbalanced growth was the result of a situation where politicians in developing countries become more focused towards economic growth rather than a balanced development (Bodorkos and Pataki, 2009). Even in Iran, establishments 
exploiting the huge maritime, mineral and agronomic resources offering business and employment opportunities sometimes cause detriment to the zone's prosperity (Afrakhteh, 2006). This phenomenon is vividly observed in SPSEEZ in Iran.

\section{Literature review}

\subsection{Back ground of the Case study}

SPSEEZ zone contains $3.4 \times 10^{12}$ standard $\mathrm{m}^{3}$ of natural gas or even more, which is around $6 \%$ of the world fossil sources (Najibi et al, 2008). It is undergoing rapid development as an economic pole in regional and national economy (Mokhtarany, 2006). The purpose of development of this area was to harvest petroleum and its related products. This area covers 14,000 squares kilometers and is located in the southern coastal area of Iran and north of Persian Gulf where the climate is hot and humid (see figure 1).

\subsection{Sustainable planning and new urban growth}

It is generally acknowledged that sustainability needs technical, organizational and institutional change and innovation to become a reality (Hartman et al, 1997). This calls for collaboration among different actors. Collaborative approaches are the hub of dominant theoretical paradigms of industry-related discourses on sustainable development (ibid). The dominant proper economic paradigm supports the singular and competitive behaviors of cities towards sustainability (Holden et al, 2008). However, the progress towards sustainability is not satisfactory in developing countries (Saadatian et al, 2009).

It is common in developing countries that decision-makers and politicians' decisions are more skewed towards economic dimension to facilitate faster development without paying enough attention to other aspects (Caiden and Wildavsky, 2003). Usually, they do not include planners, public and other stakeholders of the community in the process.

In order to have a sustainable development, several items should be considered consecutively in development decision making process. These are: dealing transparently and systemically with risk, uncertainty and irreversibility; ensuring appropriate valuation and; appreciation and restoration of nature (Sneddon et al, 2005). It needs integration of environmental, social, human, and economic goals in policies and activities and making sure of equal opportunity and participation. This paper describes the most important needs of present residents of SPSEEZ by collecting data from the residents themselves. They were also asked to rank the needs according to their importance.

\subsection{History of urban planning system in Iran in recent decades}

Iran's urban population rapidly grew from year 1956 to 1996. During this period, it expanded about 6.4 times. From 1956 to 2003, the number of new cities in Iran increased from 199 to 900 (Statistic Center of Iran, 2003). To cater that, Iran's new constitution has been prepared in 1979, emphasized on regional planning and balancing national development (Amirahmadi, 1996). In order to address the problems of undeveloped zones, policymakers have attempted to bridge the gap between regional spatial planning and sectoral economic planning (Sharbutoghlie, 1991). For this reason, they have formulated a process to address the spatial strategy planning (Amirahmadi, 1990).

The practice of urban planning in Iran, according to Zebardast (2006), is directive and hierarchical in terms of both coverage and nature. SPSEEZ is even worse than other urban areas because the rapid industrial development caused much organic residential and commercial growth. The planning and functioning of new towns constructed prior to the revolution had been based on political and military objectives, and to provide shelter for workers in the oil industry (Ziari, 2006). However, Iranian cities are unique in the sense that they have undergone a series of drastic change factors such as war and political struggle. One remedy for coping with the mentioned problems is creating petroleum zones, which solves many economics problems such as reducing unemployment, decreasing inflation and facilitating economic growth not only for the area, but also for the surrounding region. However, negative development impacts are inevitable as the massive concentration of people and activities peak in these zones making living and working in these areas intolerable and unsustainable.

\subsection{Definitions and background of the case study}

Petroleum zone is an area where the main cause of its growth is petroleum industry. These are places located nearby petroleum or gas reservoirs or wells or near refineries or petrochemical factories or even an exporting port where the main exporting good is petroleum. The place could be an ancient village or a city, or a new city.

SPSEEZ was established in 1998 for the utilization of south Pars field gas resources. Iranian companies performed exploration of SPSEEZ, together with Qatar companies in 1972 because of their shared geographical border. Iran started exploration in 1998, 26 years later when Qatar started venturing into petroleum industry. This delay was due to Islamic revolution and war. For SPSEEZ, a Master Plan was prepared, but it came late, as rapid development was already underway even during the Plan's preparation. Organic and uncontrolled urban growth was already taking place. The changing of land use had already caused social and economic changes in local communities. In this process, international oil companies seized the opportunities to increase their share in 
world construction market. The absence of strong, coordinated and proactive policies and plan has result the development priority to pay less attention to social and environmental issues.

\section{Methodology}

This study assessed the satisfaction and views of stakeholders of SPSEEZ on sustainable development concept using survey and structured interview as well as observation. The survey was designed to assess the respondents' points of views of the existing problems in SPSEEZ, and rank them according to their importance. The study employed literature, survey, observation and interview, as they deemed the most appropriate technique to elicit the information from respondents. Besides, survey is one of the most important tools of measurement in social research (Creswell, 2002). Interview and participant observation were chosen for validation of the survey method since the former is the best way to obtain high response rate, high respondent motivation and high sample quality and the latter is a source of reliable information (Hoyle et al, 2003).

\subsection{Survey}

The study followed the six steps of Creswell (2005) guide line in accomplishing survey. Those were; 1: to define the objective of survey which was to identify the respondent perception about the most hazardous environmental problems, the most important missing infrastructures and actors role in this worsening trend as well as to identify the perceptions of different stakeholder's regarding different aspects of sustainability; 2 : to develop user-friendly questionnaire to suit the local culture and in Arabic and Persian language to be understandable for all respondents, 3: to select a suitable sampling method which probable random sampling method was selected, 4: to carry out pilot test and revise the instrument to check the accuracy and reliability, 5: to conduct the survey, and 6: to analyze the data using Statistical Package for the Social Sciences (SPSS) (See appendices 1).

The survey design was based on the most pertinent and urgent problems of SPSEEZ. Three groups of respondents were selected, consisted of managers and senior engineers, indigenous residents and immigrant workers. The survey began with short briefing given to the respondent on the purpose of the survey and an explanation about the nature of the study was done. It was expressed that the survey was a pure scientific research and was not related to any governmental, political or tax activity and all responses were strictly confidential. Some managers and senior engineers were selected as survey respondents and these surveys were carried out in their offices during afternoons and weekends in a calm atmosphere. The questionnaires were designed to take about 10 to 15 minutes to be completed.

\subsubsection{Content analyses in survey}

The study utilized content analyses technique for analyzing the open ended questions. Responses gathered from open ended answers were transcribed and coded according to themes. It was later analyzed according to the frequency of the problems being stressed by respondents (see figure 6).

\subsection{Interview}

The interview was performed to validate the survey result under triangulation strategy. The interview was constituted of the result of survey which functioned as validation of study. It was carried out on 7 senior local council members and 5 senior engineers who were working and living in SPSEEZ for the last 10 years. The saturation theory was utilized to determine the number of interviewees and the interviews were repeated until no new information was obtained. The result of interview ratified the survey. The interview process was accomplished following seven steps. Firstly, using themes so that the interview was structured according to survey finding and to double check the findings. Secondly, in getting the names and getting approval from potential respondents to be interviewed. Thirdly, conducting the interview including getting permission to tape recording or writing the conversation. Then, transcribing the recording or notes from the interviews. Next, analyzing , coding and decoding of the data as well as verifying the information with original respondent to check the reliability of the analyses. Finally writing and reporting findings.

\subsection{Observation}

The observation was performed in a range of six year period of time from 2002 to 2008. The type of the observation was participant observation and area observation and these observed phenomena were recorded in the form of writing and photos. The objective of observations was to identify the existing unsustainable obstacles, such as the lack of various infrastructures as well as to grasp the opinions of those people via observing their informal discussion among themselves. Participant observation has been regarded as one of the most common methods for qualitative research which requires that the researcher become a participant in its culture or context (Hoyle et al, 2003).

\section{Results and analyses}

This research tried to explain the significance of the problems identified by the stakeholders. In addition, it compared the attitudes of managers or decision-makers to the people's attitude. It shows the level of familiarity of people and decision- makers to the term sustainability. Finally, it discusses the roles of different actors in local sustainable development. Respondents of this research consisted of managers and senior engineers, indigenous residents and immigrant workers. According to local council announcement, the population of SPSEEZ at the 
time of this research was around 30,000 indigenous residents and 70,000 immigrants. The number of workers and immigrants, which consist of people who work in this zone and stayed only 15 to 20 days there, because their families were in another cities, was very high. This situation could have influenced the findings of this study. Local people were represented by residents of former villages who were living in that area for more than 20 years and aged more than 18 years old.

The respondents comprised of 30 managers or senior engineers, 100 indigenous residents, and 254 immigrants from other regions working as laborers, retailers, technicians and contractors. $85 \%$ of first group were high quality managers who graduated from a university while only $22 \%$ of immigrant had a university degree and $69 \%$ of indigenous were even illiterate. All of the respondents were male.

\subsection{Sampling}

The respondent's availability varied from time to time because many of those people were working or living in SPSEEZ for just 15 to 20 days a month. This is very common in most petroleum areas. In this case, stratified sampling could not be applied because it might cause bias. However, the total population of the region has always been constant; therefore, the respondents were selected based on simple random sampling. Managers and senior engineers were selected among the people who were involved in SPSEEZ for at least three years and were making decisions for more than 50 employees. Trained researchers who were familiar with the people and the region managed to survey 384 respondents as required. In designating the sample size, confidence level and confidence interval was hypothesized at $95 \%$ and 5 .

\subsection{Stakeholders and sustainability}

Literature review was employed to determine the different aspects of sustainability. There are four different aspects identified namely; Environment, Economy, Social and Policy. The result of the survey imparted that majority of managers and senior engineers (93\%), agreed that the current development is not sustainable, where $80 \%$ agreed that there is no social sustainability. $90 \%$ of them declared that the development is not environmentally sustainable; while $60 \%$ expressed that the development is neither environmentally sustainable nor economically sustainable.

Regarding the perception of indigenous residents, 75\% agreed that the current development is not sustainable and $65 \%$ answered that there is not enough social sustainability. $68 \%$ declared that it is not environmentally sustainable and $75 \%$ claimed that there is neither environmental sustainability nor economic sustainability.

Finally, $70 \%$ of the immigrants agreed that the current development is not sustainable and $71 \%$ imparted that there is a lack of social sustainability. $74 \%$ declared that there is a lack of environmental sustainability and 59\% agreed that there is neither environmental sustainability nor economic sustainability (see figure 2). This shows that all three groups of respondents unanimously agreed that there are not enough sustainable efforts, especially for social sustainability followed by environmental sustainability.

In regard of the most important environmental problems, the survey results showed that; $67 \%$ of managers regarded air pollution as the most important issue followed by waste management $(17 \%) .13 \%$ of them selected water pollution while only $3 \%$ selected noise pollution as the most environmental hazardous problems.

From the view of the indigenous residents, $50 \%$ declared that air pollution is the most hazardous environmental problem while $30 \%$ expressed the waste management issue. $20 \%$ agreed that it is water pollution and nobody endorsed noise pollution as a problem.

Finally, among the immigrants, $63 \%$ chose air pollution as the biggest problem and $25 \%$ viewed that it was water pollution. $12 \%$ saw waste management as the most hazardous environmental problem and none of immigrants endorsed noise pollution (see figure 3). The results gave statistical evidences that air pollution is considered by the respondents as the top environmental problem and noise pollution as the least important. This is due to high level of pollutants and suspended materials on air during daytime, stemming from the petroleum industry (Mokhtarany, 2006).

Providing sufficient basic infrastructure means fulfilling and satisfying the needs of present generation (Sneddon et al, 2005). Therefore it is considered as one of the factors which could contribute to sustainability. In this regard the most important problems identified by managers and senior engineers, indigenous residents and immigrants are another part of finding. For the managers, $40 \%$ regarded the inconsistency in electricity supply is the most important problem while $27 \%$ asserted that the lack of sanitation and health center near residence quarters is the most important problem. In addition, $23 \% \mathrm{knew}$ the lack of potable water as the most important problem and only $10 \%$ asserted the lack of gas line is the most important problem.

Similarly, among the indigenous residents, 37\% asserted that the lack of electricity is the major issue while 35\% chose the lack of sanitation and health center near residence quarters. 15\% declared that the lack of Gas line is an issue and $13 \%$ announced it is lack of potable water.

However, from the immigrants' point of view, more than one thirds $(38 \%)$ asserted that the lack of sanitation and health center near residence quarters is an issue while $36 \%$ declared that the lack of electricity is the most 
important problem. $14 \%$ asserted that it is lack of gas line and the remaining $12 \%$ declared that it is lack of potable water.

This result shows that majority of respondents viewed insufficient supply of electricity as the most important problem in SPSEEZ. This is exacerbated by high reliance to air conditioner due to the hot climate.

Figure 5 illustrates the findings on the actors that respondents think, have the highest responsibility and could instill change for current unsatisfactory and unsustainable actions particularly in waste management and recycling. This figure indicates that majority of stakeholders $(93 \%)$ believe that the politicians have the most impressive role in this unsustainable situation. Consecutively, the burden should be shouldered by the petroleum companies, local authorities, consulting companies (in preparing Master plan). The list continues with public, small business and shops, teachers, cooperation, NGOs, children and school students that have been identified as the most important actors in changing the current situation to a sustainable situation.

The last part of the survey attempt to seek opinion on "who is most responsible for this chaotic situation and what should they do?" At the same time, it also tried to explore how these actors could influence a sustainable trend shown in table one. In this part the open ended questions were utilized to give the respondents freedom to write down their own interpretation of the existing challenges. The answers were analyzed and categorized using content analyses technique (see table 1 and figure 6). Table 1 illustrates the role and responsibilities of different actors in supporting sustainable development according to responses collected from respondents. They have comprehensively identified different actors and their respective roles such as the politicians should prepare programs and policies for sustainable city management and continuously monitor and assess these programs and policies.

\section{Conclusion}

Sustainable development especially in SPSEEZ means that the productive sectors of the economy must be well managed, to reach equality or balance in other sustainable dimensions. The current pace of the development of the area was seen as unsustainable by majority of residents. Based on the three groups of respondents which consist of managers, indigenous residents and immigrants, it appeared that although majority of the respondents agreed that this development is an excellent pace towards better economy, they also believed that it is not sustainable. The result of the study shows that environmental problems are considered the first challenge and social problems come second. This research also finds that the people in SPSEEZ agreed that politicians and decision-makers are primarily responsible for this trend. After them, the petroleum companies and local authorities are perceived to be responsible. The absence of legally binding plan to guide development from the very beginning could be the cause of current uncontrolled and chaotic development of SPSEEZ. Therefore, considering the social and political condition, the top-down intervention and the need of a good political will to steer the development is highly needed and seen by the people as the best way to solve the problems.

\section{Acknowledgment}

The result of this study is a part of at Dour Andish Baharah Oil and Gas Research group, with collaboration with UPM's scholars. The paper would like to acknowledge Assoc. Prof. Dr Rahinah Ibrahim Deputy Dean of Faculty of Design and Architecture Universiti Putra Malaysia, in this study.

\section{References}

Afrakhteh, H. (2006). The problems of regional development and border cities: A case study of Zahedan, Iran. Cities, 23(6), 423-432.

Amirahmadi, H. (1996). Iran's development: evaluation and challenges'. Third World Quarterly, 17(1), 123 - 148

Blowers, A. (1997). Planning for a sustainable environment: A report by the Town and Country Planning Association. Earth scan Publications Ltd.: London.

Bodorkós, B., \& Pataki, G. (2009). Linking academic and local knowledge: community-based research and service learning for sustainable rural development in Hungary. Journal of Cleaner Production, 17(12), 1123-1131.

Briassoulis, H. (2002). Sustainable tourism and the question of the commons. Annals of Tourism Research, 29(4), 1065-1085.

Caiden, N., \& Wildavsky, A. B. (2003). Planning and budgeting in poor countries (Vol. 1). New Jersy: Simon Schwartzman.

Calò, F., \& Parise, M. (2009). Waste management and problems of groundwater pollution in karst environments in the context of a post-conflict scenario: The case of Mostar (Bosnia Herzegovina). Habitat International, 33(1), 63-72.

Choguill, C. L. (2008). Developing sustainable neighborhoods. Habitat International, 32(1), 41-48.

Clifton, D. (2009). Security and a Sustainable World. Journal of Sustainable Development, 2(3), 3-17. 
Creswell, J. W. (2005). Research design: qualitative, quantitative, and mixed method approaches (Vol. 1). London: SAGE.

Hartman, C. L., \& Stafford, E. R. (1997). Green alliances: building new business with environmental groups. Long Range Planning, 30(2), 184-196.

Holden, M., Roseland, M., Ferguson, K., \& Perl, A. (2008). Seeking urban sustainability on the world stage. Habitat International, 32(3), 305-317.

Karsheans, M. (1991). Oil, state and industrialization in Iran. Tehran: Safa.

Mandeli, K. N. (2008). The realities of integrating physical planning and local management into urban development: A case study of Jeddah, Saudi Arabia. Habitat International, 32(4), 512-533.

Mitich, M. (2010). Sustainable Approaches to A Reform of Coal Mining Industry in Serbia. Journal of Sustainable Development, 3(1), 62-69.

Mokhtarany, B. (2006). Report: Future industrial solid waste management in Pars Special Economic Energy Zone (PSEEZ), Iran Waste Management \& Research, 24(3), 283-288.

Najibi, H., Rezaei, R., Javanmardi, J., Nasrifar, K., \& Moshfeghian, M. (2009). Economic evaluation of natural gas transportation from Iran's South-Pars gas field to market. Applied Thermal Engineering, 29(10), 2009-2015.

Nghia, N. C. (2010). Management Research about Solutions for the Eradication of Global Poverty: A Literature Review. Journal of Sustainable Development, 3(1), 17-29.

Osman, M. T. (2006). Sustainable Urban Landscape: Making the case for the Development of an Improved Management System. International Journal of Sustainable Tropical Design, 1(1), 17-23.

Saadatian, O., Salleh, E. I., Osman, M. T., \& Kamariah ,D. (2009). Observations of Sustainability Practices in Malaysian Research Universities: Highlighting Particular Strengths, Pertanika Journal of Social Science 17 (2), $293-312$

Saleh, M. A. E. (2004). Planning issues in the Middle East, an introduction. Habitat International, 28(4), 501-503.

Sharbatoghlie, A. (1991). Urbanization and Regional Disparities in Post-revolutionary Iran. London: Westview. Sneddon, C., Howarth, R. B., \& Norgaard, R. B. (2006). Sustainable development in a post-Brundtland world. Ecological Economics, 57(2), 253-268.

Statistic Centre of Iran. (2003). South Pars Special Zone report. Tehran: Nashr Press.

Zebardast, E. (2006). Marginalization of the urban poor and the expansion of the spontaneous settlements on the Tehran metropolitan fringe. Cities, 23(6), 439-454.

Ziari, K. (2006). The planning and functioning of new towns in Iran. Cities, 23(6), 412-422.

Table 1. Important Actors in Sustainable Development and Their Roles

\begin{tabular}{|c|c|c|}
\hline No & Actors & Their roles and function in sustainability \\
\hline 1 & Teachers & $\begin{array}{l}\text { Influence and teach students the importance of recycling, greening, sustainable energy, etc. } \\
\text { Push this concept to become a culture }\end{array}$ \\
\hline 2 & Small business & $\begin{array}{l}\text { Encourage employees, customers, supplier colleagues to follow the sustainable way. Put } \\
\text { recycling bins inside and outside enterprises for passers using sustainable energy etc. }\end{array}$ \\
\hline 3 & Public & Try to source reduction and source segregation - Help local authorities to operate properly. \\
\hline 4 & Politicians & $\begin{array}{l}\text { Lead local authorities toward sustainable management. Contribute funds for sustainable } \\
\text { initiatives, recycling and waste management programs- Make sustainability a priority- } \\
\text { monitor and assess the programs via preparing good policy. }\end{array}$ \\
\hline 5 & $\begin{array}{l}\text { Petroleum } \\
\text { companies }\end{array}$ & $\begin{array}{l}\text { Follow the requirement of industrial waste management -Teach employees to understand the } \\
\text { advantages of sustainability, recycling and waste management. Interact with suppliers, } \\
\text { consumers, transportation companies and other contractors to apply the concept of } \\
\text { sustainability in their mission and activities. Ensure that not only they understand and take } \\
\text { grave actions on their territory based on sustainable manner but also spread this message } \\
\text { across the SPSEEZ. }\end{array}$ \\
\hline 6 & NGO & Lead communities to participate and support sustainability issues \\
\hline 7 & Local authority & $\begin{array}{l}\text { Keep sustainability issues like recycling a priority, provide the necessary facilities, have a } \\
\text { professional and trained staff that implement legislation and punish infringers. }\end{array}$ \\
\hline 8 & Cooperation & Sponsor sustainability programs, spread this culture among people \\
\hline 9 & $\begin{array}{l}\text { Consulting } \\
\text { companies }\end{array}$ & $\begin{array}{l}\text { Keep sustainability issues in mind during planning. Remind investors and government the } \\
\text { advantages of sustainable development. }\end{array}$ \\
\hline 10 & $\begin{array}{l}\text { Students and } \\
\text { children }\end{array}$ & $\begin{array}{l}\text { Cooperate in sustainable program like garbage segregation. } \\
\text { Teach their parents and their family members Sustainability lessons. }\end{array}$ \\
\hline
\end{tabular}




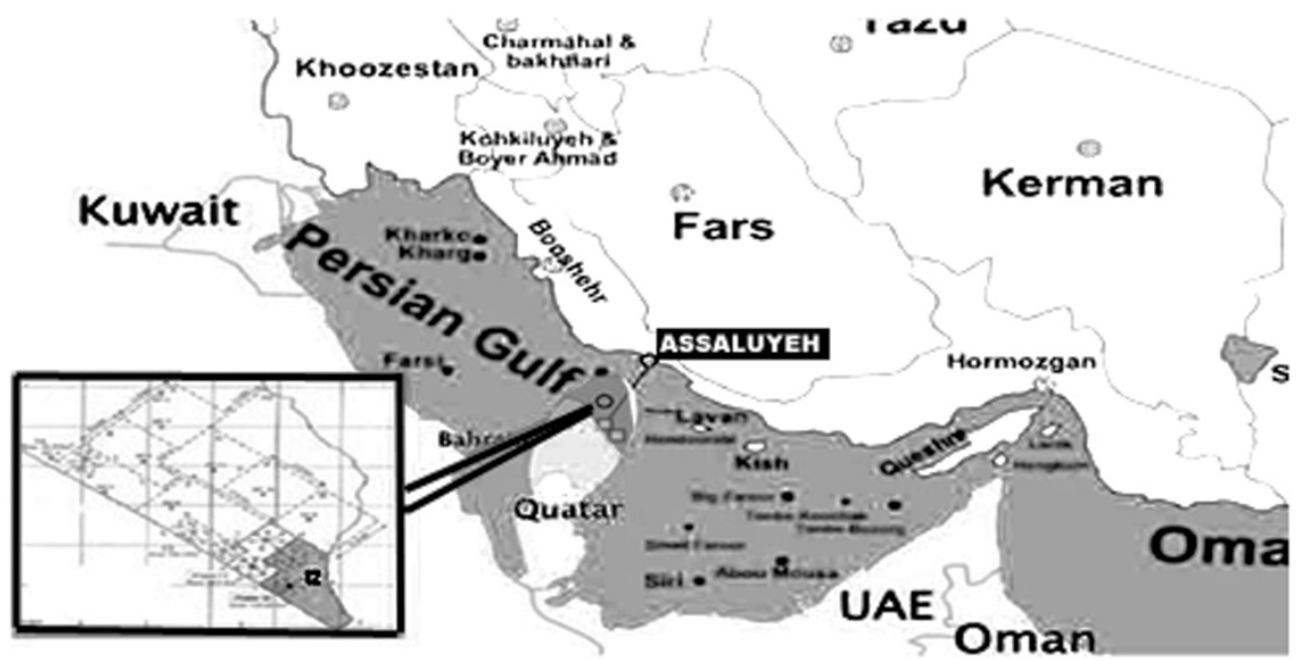

Figure 1. Location of SPSEEZ in the Middle-East

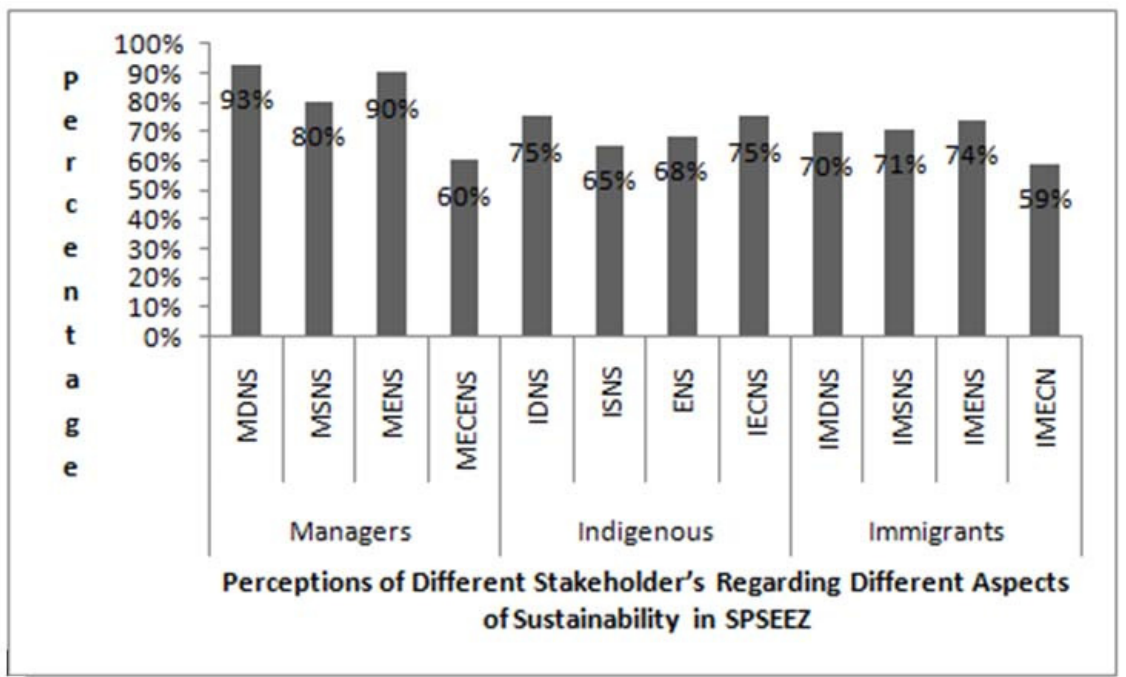

MDNS: Manager think development is not sustainable

MSNS: Managers think the region is not socially sustainable

MENS: Managers think the region is not environmentally sustainable

MECNS: Mangers think the region is neither environmentally nor economically sustainable IDNS: Indigenous think that development is not sustainable

ISNS: Indigenous think region is not socially sustainable

IENS: Indigenous think region is not environmentally sustainable

IECNS: Indigenous think the region is neither environmentally nor economically sustainable IMDNS: Immigrants think that the development is not sustainable IMSNS: Immigrants think the region is not socially sustainable IMENS: Immigrants think the region is not environmentally Sustainable

IMECNS: Immigrant think that the region is neither environmentally nor economically Sustainable

Figure 2. Perceptions of Different Stakeholder's Regarding Different Aspects of Sustainability in SPSEEZ 


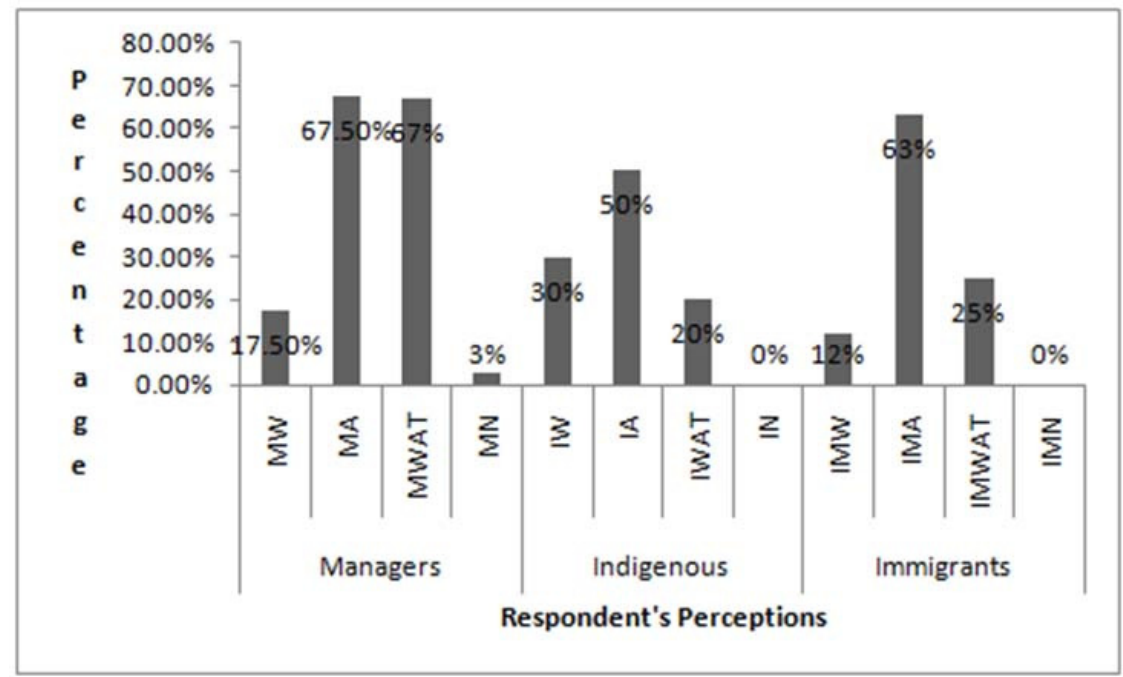

MW: Managers took waste problems as the most hazardous issue MA: Managers took air pollution as the most hazardous issue MWAT: Managers took water pollution as the most hazardous issue MN: Manager took noise pollution as the most hazardous issue

IW: Indigenous took the waste as the most hazardous issue

IA: Indigenous took the air pollution as the most hazardous issue

IWAT: Indigenous took water as the most hazardous issue

IN: Indigenous took noise as the most hazardous issue

IMWAT: Immigrants took water as the most hazardous issue

IMW: Immigrant took waste as the most hazardous issue

IMA: Immigrant took the air as the most hazardous issue

IMN: Immigrant took the noise as the most hazardous issue

Figure 3. Respondent's Perceptions about the Most Hazardous Environmental Problems

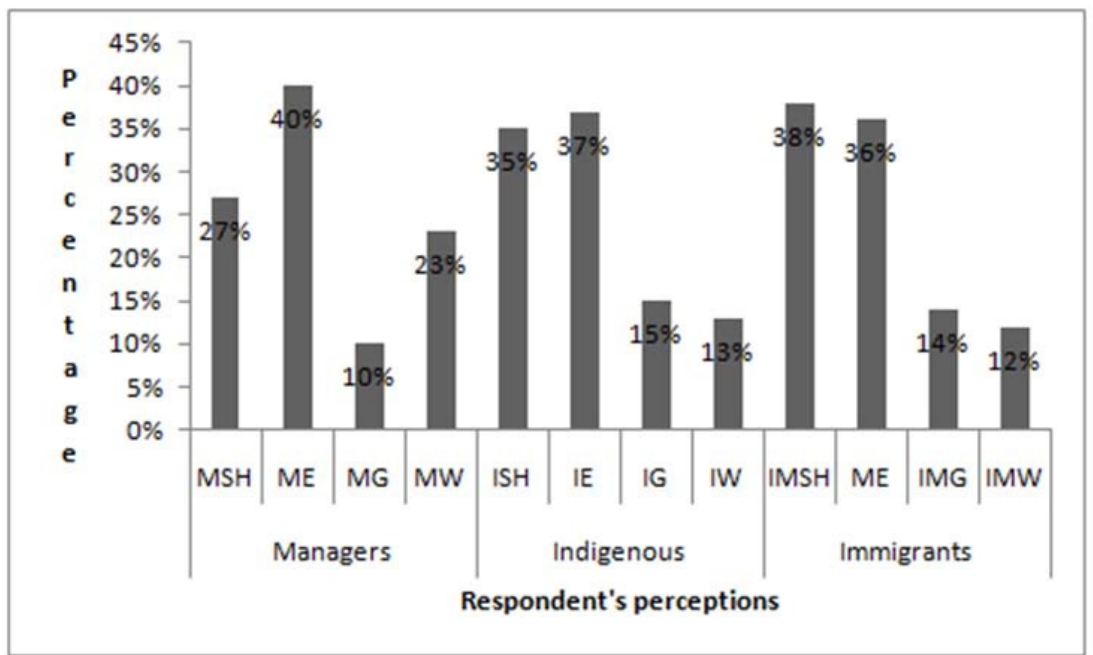

MSH: Managers took the lack of sanitation and health as the most important missing infrastructure ME: Managers took the lack of electricity as the most important missing infrastructure MG: Managers took the lack of gas as the most important missing infrastructure MW: Managers took the lack of water as the most important missing infrastructure ISH: Indigenous took the lack of sanitation and health as the most important missing infrastructure IE: Indigenous took the lack of electricity as the most important missing infrastructure IG: Indigenous took the lack of gas as the most important missing infrastructure IW: Indigenous took the lack of water as the most important missing infrastructure IMSH: Immigrants took the lack of sanitation and health as the most important missing infrastructure IME: Immigrants took the lack of electricity as the most important missing infrastructure

IMG: Immigrants took the lack of gas as the most important missing infrastructure

IMW: Immigrant took the lack of water as the most important missing infrastructure

Figure 4. Respondent's Perceptions about the Most Important Missing Infrastructures 


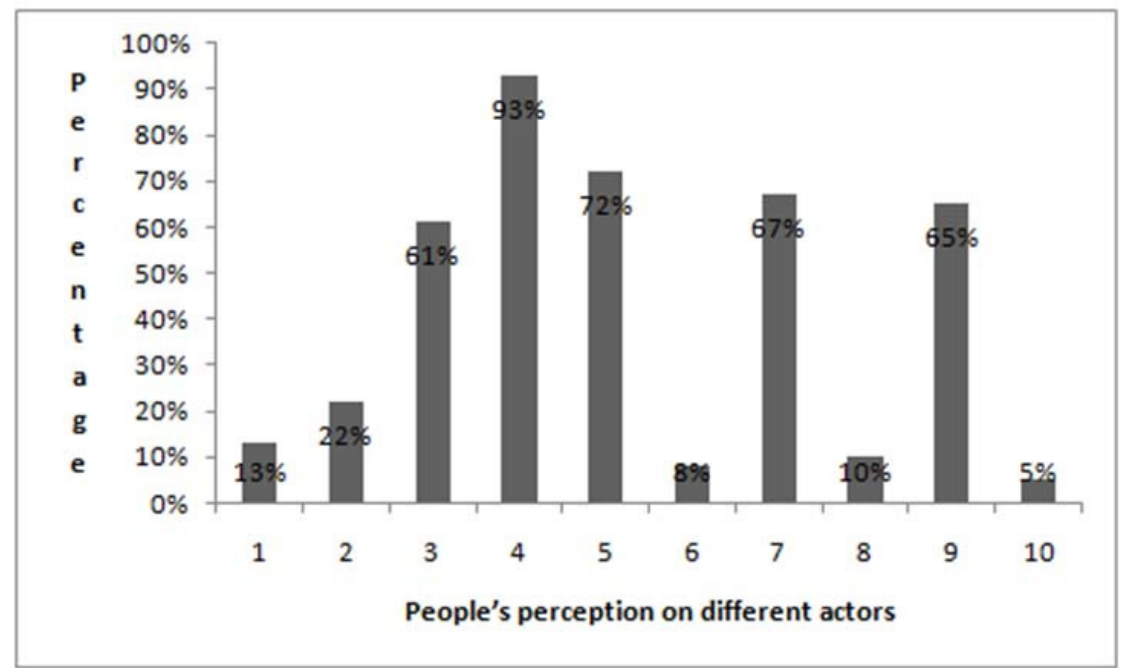

1-Teachers

2-Small business

3-Public

4-Politicians

5-Petroleum companies

6-NGO

7-Local authority

8- Corporation

9-Consulting companies

10-Childeren and school students

Figure 5. People's Perception and Actor's Role in This Worsening Trend

Categorizing the answer based on 10 subjects of the role of different actors

$+$

Content analyses Technique

Identifying most repeated key phrases

Report (Table one)

Figure 6. Flow Diagram and Content Analyses Technique 


\section{Appendices}

Translation of Questionnaire Tool

1-Do you think the current development in SPSEEZ satisfies your needs and will satisfy the needs of your children?

$\square$ Yes $\quad \square$ No $\quad$ Undecided

2- Which of the following subjects is considered a challenge for satisfying your needs as well your future generation needs? (You can tick all, two or one of them)

1- $\square$ Environmental problem 2- $\square$ Social Problem 3- $\square$ Economical Problem 4- $\square$ Undecided

3- Which of the following subjects is considered the most important environmental challenge? (Tick one)

1- $\square$ Air pollution 2- $\quad$ Noise pollution 3- $\quad$ Waste management 4- $\square$ Water Pollution 5- $\square$ Undecided

4- Which of the following subjects is considered the most important missing infrastructure? (Tick one)

1- $\square$ Sanitation and health 2- $\square$ Electricity 3- $\square$ Gas 4- $\square$ Potable water

5- $\square$ Undecided

5- Who are responsible for worsening this trend? (You can click more than one)

1- $\square$ Teachers, 2- $\square$ Small business, 3- $\square$ Public, 4- $\square$ Politicians, 5- $\square$ Petroleum companies’ 6- $\square$ NGO

7- $\square$ Local authority, 8- $\square$ Corporation, 9- $\square$ Consulting companies, 10- $\square$ Children and school students

6- Explain how can the 10 actors of question number five improve the situation?

7- You are considered as (Tick one only)

1- $\square$ Indigenous

2-口Immigrant

3- $\square$ Manager

8- Gender

1- $\square$ Male

2- $\square$ Female

9- Level of study

1- $\square$ Bachelor and above 2- $\square$ Secondary, High school, $\quad 3-\square$ Illiterate

10- Age

1- $18-35$

$2-\square 35-50$

$3-\square 50-70$ 